\title{
Mesenchymal stem/stromal cells: the therapeutic effects in animal models of acute pulmonary diseases
}

\author{
Sirous Sadeghian Chaleshtori, ${ }^{1,2}$, Mohammad Reza Mokhber Dezfouli, ${ }^{1,2^{*}}$ and Massoumeh Jabbari Fakhr ${ }^{2,3}$
}

\begin{abstract}
The pulmonary diseases are one of the most important causes of death in the world. The successful therapies in the field of lung diseases are very limited and the medical treatments available are ineffective in many of the lung diseases. Many studies have evaluated the new therapies in the acute pulmonary diseases, and the transplantation of mesenchymal stem/stromal cells (MSCs), which is a branch of cell therapy, has a special place among the new medical techniques. The MSCs are present throughout the body and are thought to play a role in tissue regeneration and inflammation control. In the event of injury, the local MSCs traverse the shortest possible distance from the tissue or blood vessels to reach the affected site. But, there are few undifferentiated cells in the tissues. The exogenous MSCs are used to immunity modify or regenerative treatments in preclinical models of acute pulmonary diseases. Several studies have shown the positive effects of MSCs replacement in the acute lung disorders. The effection mechanism of the MSCs include the differentiation ability and the secretion of paracrine agents such as the anti-inflammatory mediators. Many studies suggest that this treatment method is safe and is probably to be widely used in future clinical trials. This review will describe the therapeutic effects of the MSCs in the experimental models of the acute pulmonary diseases for use as a method of treatment in clinical trials in future.
\end{abstract}

Keywords: Mesenchymal stem/stromal cells, Pulmonary diseases, Therapeutic effects

\section{Importance of pulmonary diseases}

The acute pulmonary diseases in all countries of the world cause irreparable damage and the mortality rate of pulmonary involvement is high worldwide. The reports show a different and widespread mortality rate for the various pulmonary diseases. For example, a systematic review shows that the acute respiratory distress syndrome (ARDS) mortality is $36-44 \%$ [1].

With regard to the anatomy and physiology of the lung tissue and successive contact with organic and nonorganic substances, despite the existence of multi-faceted

\footnotetext{
* Correspondence: mokhberd@ut.ac.ir

${ }^{1}$ Department of Internal Medicine, Faculty of Veterinary Medicine, University of Tehran, Tehran, Iran

${ }^{2}$ Institute of Biomedical Research, Faculty of Veterinary Medicine, University of Tehran, Tehran, Iran

Full list of author information is available at the end of the article
}

defense mechanisms and the advanced intrinsic and acquired immune defense system, this organ is regularly exposed to pathogens that result in damage to the structural cells [2]. On the other hand, large amounts are spent on diagnosis, hospital care, outpatient services, emergency services, drug therapy and self-care for patients with the acute pulmonary diseases, annually.

Stem/stromal cells transplantation is a branch of cell therapy that has a special place among the new medical methods. Many studies suggest that this treatment method is safe and most probably will be widely used in future clinical trials [3]. Today, the MSCs-based cell therapy is a promising method for treatment of acute diseases of the lung. Regarding the nature and the ability of MSCs in secreting the different paracrine agents, such as growth factors, the endothelial and epithelial permeability regulatory 
factors and the anti-inflammatory cytokines are effective in the treatment of acute pulmonary disorders $[4,5]$.

\section{Pathophysiology of pulmonary diseases}

A pulmonary disease may be the result of involvement of the respiratory airways, the lung parenchyma or the blood vessels. A combination of these disorders is seen in many pulmonary diseases. The pathogenesis of pulmonary diseases includes damage to the lung capillaries endothelial cells, damage to the alveolar epithelium, followed by accumulation of protein-rich fluids, cellular lesions in the alveolar space and the inflammation of airways that cause resistance to air flow and the lung capacity reduction [6,7]. At the cellular level of the lungs the invasion of polymorph nuclear leukocytes (PMNs), including the neutrophils and cytokines to the lung capillaries also occurs, then their placement and adhesion to the endothelium, followed by an acute inflammatory reaction. Neutrophil is the first cell that goes into inflammation site and secretes strong antimicrobial agents, including oxidants, proteases, platelet activating factors, leukotrienes and cationic peptides. The alveolar macrophages secrete and active neutrophils are the inflammatory mediators that interrupt the epithelial fluid transfer and production of surfactant by the alveolar type II (ATII) cells [8].

The direct consequence of infection and subsequent inflammation is imbalance in the fluids of the lung capillaries and increased lung permeability, which disturbs the endothelial cells of the capillaries. With the breakdown of these cells, congestion occurs in the lung veins. Initially, additional fluid interstitial lung tissue is taken by the lymph system and returned to the vascular system. Hydrostatic forces change from capillary endothelium damage. Continuous fluid accumulation is affected lymphatic drainage and hydrostatic forces, and excess fluid to the alveolus leads to non-cardiac edema. Damage to the capillaryalveolar barrier changes the active transfer of sodium and leads to impaired clearance of the edema fluid from the alveolar spaces. Pulmonary edema is caused by irregular function of ionic channels in alveolar cells $[7,9]$.

Also, pathologic permeability of the vessels, the gap in the capillary-alveolar barrier and necrosis of the alveolar type I (ATI) and ATII cells lead to the formation of a hyalin membrane and destroying surfactant, which reduces the pulmonary capacity and disturbs the exchange of respiratory gases causing hypoxia and hypercapnia. Finally, fibroblastic secretions can lead to collagen deposition, fibrosis and worsening of the disease [10]. Many patients develop deep muscle weakness and as a result, respiratory failure occurs and their quality of life decreases.

\section{The process of pulmonary repair in injury/ inflammation}

The process of lung repair after injury/inflammation is a complex phenomenon. Endogenous stem/stromal have potency for healing injured epithelium via adaptation their structure and function. The experiment on epithelium repair of airways show that the recovery process of airway epithelium such as differentiation, migration of adjacent epithelial cells to cover the empty region, proliferation of precursor cells to restore cell number and differentiate of cells to restore the function of epithelial cells [11].

Airways epithelium immediately after injury, begins a recovery process to restore integrity to the air-blood barrier. The ATII cells proliferate and differentiate into the ATI cells, which restore the integrity of the epithelial coating and create the osmotic gradient. This osmotic gradient causes the fluid to flow out of the alveoli and into the small vessels and lymph nodes. The antiinflammatory cytokines disable the harmful neutrophils and then the neutrophils are apoptosis [12].

Active PMNs act to repair lung damage by secreting a range of destructive factors, including elastase neutrophil, metalloprotease, other proteolytic enzymes and oxidants that are effective in improving lung function. Simultaneously, the macrophages and alveolar cells remove protein compounds from the alveoli and improve the lungs [12]. There are also chemokine-dependent migratory macrophages that can contribute in the recovery process by releasing cytokines and apoptosis-inducing molecules [13].

\section{Challenges facing pulmonary diseases}

When the damage to the lung and airway is more than the compensatory power of the restorative mechanisms, treatment should begin immediately. The successful therapies in the field of lung diseases are very limited and the drug treatments available are ineffective in many lung diseases [14]. Many studies have evaluated the new therapies in pulmonary diseases, which focus on manipulating inflammatory pathways at various levels, reducing vascular disorders, reducing lung oxidative damage and optimizing lung tissue repair. The current therapies are based on mechanical ventilation and oxygen membranes, neuromuscular blocking agents, proper fluid delivery, oxidants, surfactants, corticosteroids, antimicrobial treatment and use of steroids and beta-agonists $[1,15,16]$. The diseases of interstitial lung tissue causes gradual fibrosis and dyspnea, and do not respond to existing treatments [14]. Despite the advancement of therapeutic approaches, lung transplantation remains the only therapeutic strategy for many patients, which it is not feasible due to lack of donor tissue or shortage of suitable donor. Severe lung donor shortage causes many patients on the waiting list to die before transplantation [2]. In addition, lung transplantation has poor potential in treating patients, and the transplanted lungs have a lifetime low. The researches show that within 5 years after transplantation, about $50 \%$ and during 10 
years, $75 \%$ of the transplanted patients lose their lives. On the other hand, in successful transplantations, the lifelong need for immunosuppressive drugs will cause many problems and costs for the patient [17]. Therefore, the development of preventive approaches and the new therapies are important to reduce pulmonary diseases and improve the quality of life.

Today, the treatment of diseases has shifted to cell therapy, tissue engineering and gene therapy. Recent findings suggest that embryonic stem cells and stem/ stromal cells isolated from adult tissues may play a role in restoration and repair of the damaged tissues $[3,18]$. The most common clinical application of stem/stromal cells is related to the bone and cartilage tissues, the urinary tract, the nervous system and cancers. In the field of lung and airways, due to the specific physiological complexities, little research has been done on the treatment with stem/stromal cells. With regard to the high proliferative power and the ability to multi-lineage differentiate MSCs and, in particular, because of their significant role in the effects of immune modification $[19,20]$, these cells can be used as a practical tool for cell therapy purposes for treating a large number of degenerative diseases and congenital disorders.

\section{Stem/stromal cells and precursor cells}

The stem/stromal cells are defined as non-specific cells that have significant potential for conversion into a variety of cell types. These cells can restore the place of damaged cells with a system of internal restoration [21]. Most organs of the body have a small reservoir of stem/ stromal cells that is capable of proliferation, differentiation into precursor cells, replace old cells and repair minor injuries [22]. The potential sources of precursor cells are identified for epithelium of the lung and airways and are divided into two groups: the endogenous and exogenous stem/stromal cells.

\section{Endogenous stem/stromal cells}

The undifferentiated endogenous stem/stromal cells play roles in the repair and maintenance of all body tissues. There are few undifferentiated cells in the tissues that are often converted into the differentiated cells in the tissue [23]. The lung is a complex organ with more than 40 different and distinct cell types, of which there are different populations of ancestral cells in different anatomical regions along the lung bronchial tree [17].

The researches have shown that lung cells are mature and differentiated and have different phenotypes. In addition to the fundamental role of lung precursor and endogenous cells in repairing the damage, reversible phenotype in the epithelial cells and mucus plays an important role in repairing the damage [24]. Although improvements have been made in clarifying the identity and role of the lung airways precursor cells in mice, the role of this cell population remains uncertain and there is little information in humans and the other animal models. Types of endogenous stem/stromal cells in the lung and airways include: basal cells in the trachea and the upper parts of the bronchi, clara cells in the lower parts of the airways, bronchoalveolar duct junction (BADJ) at the intersection of the bronchioles with the alveoli and ATII cells in the alveoli [17].

\section{Exogenous stem/stromal cells}

The ability of the lung endogenous precursor cells to repair, which is often considered as a natural regeneration capacity, decreases with age, and although damage can be quickly and completely recovered by precursor cells, these cells are not usually enough to compensate widespread injuries. The purpose of transplantation of exogenous stem/stromal cells (such as embryonic, adults, etc.) is to replace damaged cells or dead cells. The transplantation of autologous or allogenic cells in models of animal has indicated that cells can be replaced in the lung and differentiated into the adult epithelium phenotypes and as a result, increased cellular response to damage [25]. Exogenous stem/stromal cell-based therapies, including MSCs, has created a new approach to acute diseases of the lung.

\section{Mesenchymal stem/stromal cells}

The MSCs are present throughout the body and are thought to play a role in tissue regeneration and inflammation control. In the event of injury, the local MSCs traverse the shortest possible distance from the tissue or blood vessels to reach the affected site. The isolated MSCs from adipose tissue, blood or bone marrow are released in response to inflammation and absorbed through the lymph nodes and blood vessels by the chemokine-dependent mechanism [26]. The MSCs are cells with high proliferation and selfhealing. The differentiation power of these cells in vivo and in vitro has led them to be considered as a good tool for regenerative medicine and tissue engineering. With regard to the high proliferation and the ability MSCs differentiation and also because their prominent role in the effects of immune modulation, the ability to migrate to injury sites, the secretion of growth factors, anti-inflammatory cytokines, extracellular vesicles as well as action through differentiation and cell-cell junction $[19,20,27,28]$ can be used as an applied tool for the purpose of cell therapy for the treatment of congenital disorders, degenerative diseases, autoimmune diseases and also as efficient carriers to deliver treatment to specific areas $[15,29]$.

The studies have shown that cell therapy is more effective in the acute phase of pulmonary diseases such as obstructive pulmonary disease (COPD), idiopathic pulmonary fibrosis (IPF), bronchopulmonary dysplasia (BPD), cystic fibrosis 
(CF) and ARDS than other conflicts [17]. The recent studies have displayed the effects of paracrine in these cells, such as angiogenesis stimulation, adjustment of inflammatory conditions and immune responses in animal models of pulmonary diseases [27, 28]. A new therapeutic strategy using MSCs causes the significant decline in the acute pulmonary inflammation induced by Lipopolysacaride (LPS) in the animal models of mice [27, 28, 30], rabbit [5] and sheep [31].

A part of the transplanted MSCs in pulmonary diseases migrates to the site of injury and inflammation and creates beneficial effects. The other part may affect the other cells by tissue restorative mediators or immune modulation. The MSCs are able to express a wide range of the chemokine receptors and migrate based on the chemokine slope. Most chemokines have an effect on tumor necrosis factor$\alpha$ (TNF- $\alpha$ ), and MSCs mobilization and their migration to damaged tissues depends on the systemic and topical inflammation amount [32]. The duration of cell culturing and the amount of cell culture have a significant effect on the morphology, differentiation, survival and migration characteristics of the MSCs [33]. The MSCs immediately after isolation have the ability to migrate more quickly than the cultivated MSCs [32, 34]. The different preparation conditions of MSCs make a difference in the cell phenotype and the expression of the migratory receptors, and this may lead to differences in their therapeutic effects [26]. Therefore, culture condition is a powerful and effective tool in the effects of cellular therapies.

\section{Therapeutic function MSCs}

The exogenous MSCs are used to immunity modify or regenerative treatments in preclinical models of various diseases. Several studies have shown the positive effects of MSCs replacement in the acute lung disorders. The MSCs migration also depends on transplantation route. Most studies have used intravenous route [30, 35-39] and a large portion of the MSCs is trapped in the lungs during the first pass [40]. Escape from the lung trap may improve the survival of the MSCs and affect cell distribution and its therapeutic effects after transplantation. In the arterial infusion, there is more certainty about the MSCs reaching target organ. After $24 \mathrm{~h}$, the MSCs move to the other organs, especially the liver and the spleen, and appear in the injured tissue [26].

In inflammatory conditions, the MSCs express Indolearnine 2, 3-dioxygenase (IDO), which plays an important role in the production of regulatory $\mathrm{T}$ cells [41]. The MSCs induce regulatory $\mathrm{T}$ cells by increasing the Interlukine-2 (IL-2) level, this occurs when active T cells are inhibited by the MSCs [42]. In addition, after the MSCs transplantation, monocytes as a very important mediator cell become the macrophages of type II. The type II macrophages, produce Interlukine-2 (IL-2) (IL-
10) and chemokine (C-C motif) ligand 18 (CCL18), which result in the induction of regulatory $\mathrm{T}$ cells [26]. Overall, these studies indicate the effects of MSCs on the immune system in acute pulmonary injury in the models of mice and human, and provide important preclinical information for clinical trials of the MSCs in the pulmonary diseases.

Different mechanisms of paracrine, including the release of anti-inflammatory mediators such as IL-10, prostaglandin E2 (PGE2) [43], angiopoietin-1 [44] and keratinocyte growth factor (KGF) [45], have been proposed to justify the therapeutic effects of the MSCs. Transplantation of the MSCs results in a rapid response that may subsequently affect the other cells. The systemic nature of these responses represents that even the MSCs in the lung after transplantation can spread their effects to other sites in the body, and this may be the basis of the mechanism of treatment with the MSCs [26]. Considering all of the published information, it should be admitted that there is still little information on how the MSCs therapeutic effects work. Therefore, further studies are needed to explore the fate of the MSCs and their functional characteristics after the transplantation to allow clinicians to use the MSCs clinically.

\section{MSC therapy in the model of pulmonary diseases}

Transplantation of various types of the ancestral cells, including the mononuclear cells isolated from bone marrow, the endothelial progenitor cells, the dental pulp stem cells, the amniotic fluid cells, the hematopoietic cells, etc. have been effective in the different clinical models of the acute pulmonary diseases such as acute lung injury (ALI)/ARDS $[15,46]$.. However, the available clinical data on the effects of the isolated MSCs from bone marrow is more than the other cells. The various reports indicate the efficacy of stem/stromal cell-based therapies in the significant reduction of the acute pulmonary inflammation induced by LPS in mice [28, 30 , 47,48 ], rats [48-50], rabbit [5] and sheep [31], the pulmonary inflamma induced by oleic acid in rats [51] and pig [37], the lung inflammation caused by inhalation of smoke in sheep [36] and the inflammation of lung due to H9N2 avian influenza in mice [52] (Table 1).

Johnson et al. stated that cell therapy was commonly performed before or at the time of infection in the designed models to evaluate the effect of stem/stromal cells on damage and this is not suitable for most septic patients [75]. The results also show that the experimental model of the acute pulmonary inflammation peaks after infusion of infectious agents at $24-48 \mathrm{~h}$. Accordingly, in a study by Mokhber Dezfouli et al., transplantation of stem/stromal cell was performed $24 \mathrm{~h}$ after inflammation with maximal inflammatory symptoms, in contrast to most of the studies that have performed 
Table 1 The model of acute lung diseases in the various animal species and treatment using the MSCs

\begin{tabular}{|c|c|c|c|c|c|c|c|}
\hline & $\begin{array}{l}\text { The method of } \\
\text { inflammation }\end{array}$ & $\begin{array}{l}\text { The causative agent } \\
\text { of inflammation }\end{array}$ & $\begin{array}{l}\text { Animal } \\
\text { species }\end{array}$ & $\begin{array}{l}\text { The method of cell } \\
\text { transplantation }\end{array}$ & $\begin{array}{l}\text { Dose of } \\
\text { the cell }\end{array}$ & Source of the cell & $\begin{array}{l}\text { Type of } \\
\text { the cell }\end{array}$ \\
\hline [30] & Intratracheal & LPS & Mice & Intravenous & $2.5 \times 10^{5}$ & Bone marrow of mice & MSCs \\
\hline [53] & Intrperitoneal & LPS & Mice & Intravenous & $5 \times 10^{5}$ & Bone marrow of mice & MSCs \\
\hline [28] & Intratracheal & LPS & Mice & Intratracheal & $7.5 \times 10^{5}$ & Bone marrow of mice & MSCs \\
\hline [54] & Intratracheal & E.coli & Mice & Intratracheal & $10^{6}$ & Bone marrow of humman & MSCs \\
\hline$[49,55]$ & Intravenous & LPS & Rat & Intravenous & $10^{6}$ & Bone marrow of rat & MSCs \\
\hline [56] & Intratracheal & LPS & Mice & Intratracheal & $10^{6}$ & Umbilical cord of humman & MSCs \\
\hline [57] & Intratracheal & E.coli & Mice & Intratracheal & $10^{5}$ & Umbilical cord of humman & MSCs \\
\hline [58] & Aspiration & LPS & Mice & Aspiration & $5 \times 10^{5}$ & Bone marrow of humman & MSCs \\
\hline$[50]$ & Intrperitoneal & LPS & Mice & Intravenous & $5 \times 10^{5}$ & Umbilical cord of humman & MSCs \\
\hline [59] & Intratracheal & E.coli & Mice & Intratracheal & $7.5 \times 10^{5}$ & Bone marrow of mice & MSCs \\
\hline [60] & Intratracheal & LPS & Rat & Intrapleural & $10^{6}$ & Bone marrow of rat & MSCs \\
\hline [51] & Intravenous & Oleic acid & Rat & Intravenous & $2 \times 10^{5}$ & Bone marrow of rat & MSCs \\
\hline [61] & Intratracheal & LPS & Mice & Intravenous & $5 \times 10^{5}$ & Bone marrow of mice & MSCs \\
\hline [38] & Intratracheal & LPS & Mice & Intratracheal & $2.5 \times 10^{5}$ & Bone marrow of mice & MSCs \\
\hline$[62]$ & $\begin{array}{l}\text { Intratracheal or } \\
\text { Intrperitoneal }\end{array}$ & LPS & Mice & Intravenous & $10^{5}$ & Bone marrow of mice & MSCs \\
\hline [63] & Ventilation & Ventilator & Rat & $\begin{array}{l}\text { Intratracheal or } \\
\text { Intravenous }\end{array}$ & $4 \times 10^{5}$ & Bone marrow of rat & MSCs \\
\hline$[64,65]$ & Intranasal & LPS & Mice & Intravenous & $10^{6}$ & Adipose tissue of humman & MSCs \\
\hline [66] & Intratracheal & LPS & Mice & Intravenous & $5 \times 10^{5}$ & Bone marrow of mice & MSCs \\
\hline [67] & Intratracheal & E.coli & Mice & Intravenous & $5 \times 10^{5}$ & Bone marrow of mice & MSCs \\
\hline [68] & Intrperitoneal & LPS & Mice & Intravenous & $5 \times 10^{5}$ & Bone marrow of mice & MSCs \\
\hline [36] & Intratracheal & Smoke & Sheep & Intravenous & $10 \times 10^{6}$ & Bone marrow of humman & MSCs \\
\hline [69] & Intratracheal & LPS & Mice & Intravenous & $5 \times 10^{5}$ & Bone marrow of mice & MSCs \\
\hline$[70]$ & Intrperitoneal & LPS & Mice & Intravenous & $5 \times 10^{5}$ & Bone marrow of mice & MSCs \\
\hline [71] & Intratracheal & LPS & Mice & Intratracheal & $7.5 \times 10^{5}$ & $\begin{array}{l}\text { Bone marrow and embryonic } \\
\text { of human }\end{array}$ & MSCs \\
\hline [72] & Intratracheal & E.Coli & Rat & Intratracheal & $\begin{array}{l}2 \times 10^{6} \\
5 \times 10^{6} \\
1 \times 10^{7} \\
2 \times 10^{7}\end{array}$ & Bone marrow of human & MSCs \\
\hline [52] & Intranasal & $\begin{array}{l}\text { H9N2 avian } \\
\text { influenza virus }\end{array}$ & Mice & Intravenous & $10^{5}$ & Bone marrow of mice & MSCs \\
\hline [48] & Aspiration & Stomach contents & Rat & Intravenous & $5 \times 10^{6}$ & Bone marrow of mice & MSCs \\
\hline [27] & Intratracheal & LPS & Mice & Intravenous & $0.5 \times 10^{6}$ & Umbilical cord of human & MSCs \\
\hline [37] & Intravenous & Oleic acid & Pig & Intravenous & $2 \times 10^{6}$ & Bone marrow of human & MSCs \\
\hline$[35,73]$ & Intratracheal & LPS & Mice & Intravenous & $10^{6}$ & Menstrual blood & MSCs \\
\hline [74] & Intratracheal & LPS & Mice & $\begin{array}{l}\text { retro-orbital } \\
\text { injection }\end{array}$ & $5 \times 10^{5}$ & Adipose tissue of mice & MSCs \\
\hline [31] & Intratracheal & LPS & Sheep & Intratracheal & $5 \times 10^{7}$ & Bone marrow of sheep & MSCs \\
\hline$[5]$ & Intratracheal & LPS & Rabbit & Intratracheal & $10^{7}$ & Bone marrow of rabbit & MSCs \\
\hline
\end{tabular}

stem/stromal cell transplantation between $30 \mathrm{~min}$ and 4 $\mathrm{h}$ after inflammation. Their results indicated the significant effects of MSCs on reducing inflammation and pulmonary edema, and improvement in clinical symptoms compared with control group [5].
Although both intrapulmonary and systemic transplantation of the isolated MSCs from bone marrow lead to decrement of mortality and inflammation and improvement of alveolar fluid clearance despite the minimal transplantation of stem/stromal cells in the lung 
[76], the researchers found intrapulmonary transplantation of the human MSCs in the lung inflammation caused by Escherichia coli (E.coli) in rats [72], bone marrow mesenchymal stem/stromal cells (BM-MSCs) in the ARDS experimental model in rabbits [5] and BM-MSCs in the ARDS experimental model in sheep [31] is superior to intravenous transplantation.

\section{The effects of MSC therapy on clinical and paraclinical symptoms}

The acute pulmonary diseases cause changes in the clinical symptoms including tachycardia, tachypnea, hyperthermia, abnormal lung sounds, nasal discharge, coughing, reduced appetite, etc., and the various studies show the MSCs therapy can prevent significant changes in clinical symptoms in rabbits [5] and sheep [31]. They represented transplantation of BM-MSCs modulates the clinical sings (heart rate, respiratory rate, body temprature, appetite, physical condition and etc.) in the model of ARDS caused by LPS E.coli [5].

Simonson et al., investigated the effects of MSCs in two patients with ARDS who were resistant to treatment; breathing quality, hemodynamic conditions and failure of the other organs (liver and kidney) were recovered. Their results showed the MSCs transplantation as infusion in human causes reducion in the amount of the inflammatory cells and factors in bronchoalveolar lavage (BAL) and plasma and increases arterial oxygen pressure. In parallel, there was a decrease in various pulmonary and systemic factors, including apoptosis of the epithelial cells, alveolar-capillary fluid leakage, and proinflammatory cytokines and chemokines [77].

Zhou et al., investigated the effects of BM-MSCs in the lung injury induced by aspiration of the mouse gastric contents. In this study, the green fluorescent protein (GFP)-positive cells were administered via the tail vein. They displayed the decrement of pulmonary edema and inflammation in pathology, increase of partial pressure of arterial oxygen, the decline of protein level and the total number of cells and neutrophils in BAL, and the reduction of TNF and cytokines caused by the neutrophilic activity [48].

Also, Pedrazza et al., showed the use of adipose tissuederived MSCs in the model of LPS-induced ALI in mice caused the reduction of lung inflammation, oxidative damage and the neutrophil extracellular traps (NETs) release and a remarkable increase in the survival [74].

McIntyre et al., investigated 54 previous studies using meta-analysis, their report showed the treatment with the MSCs significantly reduced the mortality rate $(95 \%$, the confidence interval $0.18-0.34$ ). The report revealed that the deaths have reduced considering all the effective factors including the sex and model species of the study, the source of the cell, the preparation, the method of
MSCs transplantation and the clinical conditions of the acute pulmonary injury model. Also, the results of review have shown that the MSCs affect on the wide range of animal models and the experimental conditions. The surveys show that this type of treatment can be used for the many different types of lung injury in the future [78].

\section{The effects of MSC therapy on inflammation factors in BAL and blood}

Most studies have demonstrated that direct damage to cytokines involved in the inflammatory cascades contributes to lung injury [52]. In different studies it has been shown that the MSCs are able to reduce the BAL neutrophils, which are one of the most important characteristics of acute lung inflammation [30] and macrophages [63] and, on the other hand, inhibit activation and proliferation of immune cells by secreting a deterrent factor $[79,80]$. The assesment of the BAL fluids following the MSCs therapy in LPS-induced inflammation in mice has shown that the amount of inflammatory cells (especially neutrophils), cytokines (TNF- $\alpha$, interferon- $\gamma$ (IFN- $\gamma$ ) and IL6), as well as total protein, albumin and immunoglobulin M (IgM) levels is reduced [30]. The other studies confirmed the effects of the BM-MSCs administration on the decline of pro-inflammatory cytokines levels of the INF- $\gamma$, IL-1 $\beta$, IL-6, TNF- $\alpha$ and macrophage inhibitory protein-2 (MIP-2) and increase of anti-inflammatory cytokine level of the IL-10 in plasma and BAL. This despite the low level of stem/stromal cells transplantation in the lung, occurs in response to cellular contacts and soluble factors $[28,59]$. In the study of Mokhber Dezfouli et al., by evaluating cellular content and cytokines concentration of plasma and BAL, the MSCs therapeutic efficacy was investigated in ARDS-induced model by LPS in rabbits, which indicated the significant effects in modulating cellular content and cytokines concentration of BAL and Plasma. Their results displayed a decrease in the plasma concentration of the TNF- $\alpha$ and IL- 6 and an increase in the plasma concentration of the IL-10 following cell therapy with BM-MSCs in rabbits [5].

Intravenous tranplantation of MSCs causes the systemic and local decline of inflammatory cells. It has been shown that serum levels of IFN- $\gamma$, IL- $1 \beta$, and MIP are reduced following intravenous transplantation of BM-MSCs in mice [53]. Li et al. demonsterated that intravenous use of MSCs in the treatment of acute pulmonary inflammation induced by H9N2 avian influenza in mice caused a significant reduction in plasma and BAL inflammatory factors (IL- $1 \alpha$, IL-6, TNF- $\alpha$ and IFN- $\gamma$ ) and a the corresponding increase in anti-inflammatory cytokine (IL-10), 3 days after cell therapy. The researchers stated that this treatment method reduces the lung permeability and the concentration of the alveolar fluid proteins [52, 81]. 
The undifferentiated MSCs have the anti-inflammatory effects and are suitable for the improvement of LPSinduced ALI in mice [59]. The another study has shown that the administration of embryonic-derived MSCs, similar to BM-MSC, has reduced the endotoxin-induced inflammatory response, but based on the findings of gene expression, the embryonic-derived MSCs do not have the protective effect on the pulmonary edema and the protein leakage [71]. On the other hand, the researchers found that the menstrual blood-derived MSCs help to improve the permeability of the lung capillaries and reduce tissue damage and also, their beneficial effects are evident by inhibition of IL-1 and increased IL-10 in BAL and increasing the expression of the nuclear antigen and reducing the expression of caspase-3 [35]. In another study, the intravenous transplantation of adipose tissue-derived MSCs in the model of endotoxin-induced ALI in mice lead to a significant decline in protein content, neutrophil counts, and cytokines of pro-inflammatory (TNF- $\alpha$, IL-6, and MIP-2) in BAL [64].

The human umbilical cord mesenchymal stem/Stromal cells (UC-MSCs) intravenous transplantation in the acute pulmonary inflammation induced by LPS in mice prevented the inflammatory response of macrophages and increased expression of IL-10 [27]. The findings of this study showed that treatment with the UC-MSCs occurs by the secretion of paracrine agents, especially PGE2, and the factors such as IL-6 and IL-13. After transplantation of the UC-MSCs, the pathological lesions decreased and the inflammatory response including the activity of lung myeloproxidase, the amount of protein, neutrophil and expression of the various inflammatory cytokines decreased in BAL $72 \mathrm{~h}$ after transplantation. PGE2 is a paracrine agent that can affect macrophage responses and reduce inflammation. The cell therapy causes the induction decrement of inflammatory mediators, chemokines, the activity of mast cells and nuclear factor kappa B (NF-kB) and regulating in the pathway of oxidative stress formation [27]. Additionally, UC-MSCs can produce a high level of the other paracrine agents such as granulocyte macrophage colony stimulating factor (GM-CSF), granulocyte colony stimulating factor (GCSF), IL-6 and IL-13 in BAL. These factors play a key role in host defense system, proliferation and differentiation of granulocytes and mononuclear phagocytes. In response to pulmonary infections, GM-CSF can increase the number of alveolar exudative macrophages isolated from monocytes to improve host defense [27].

Recently, it has been shown that intravenous transplantation of the MSCs produces a systemic inflammatory response within a few hours after the transplantation [82]. The induction of regulatory cells may be affected by this systemic inflammatory response or by the tissue MSCs or the immune cells. The phagocytosis potential of macrophages and antimicrobial peptides increases following the cell therapy in the aveoli [52]. The active neutrophils and macrophages produce the oxygen free radicals that play an important role in the inflammatory pathways and lead to the cellular damage [1]. The lymphocytes and the group of macrophages produce the macrophage modulator cytokine (IL-10) which is an anti-inflammatory cytokine and the number of macrophages and neutrophil infiltration are reduced and modulate pro-inflammatory cytokines production and function [83]. Also, based on the results obtained from the plasma evaluation in the MSCs intrapulmonary transplantation in rabbits, it has been determined that the cell therapy has a positive effect on the immune system. The researchers indicated, the BM-MSCs in the ARDS model in rabbits resulted in the decrease in pro-inflammatory cytokines and the increase in anti-inflammatory cytokines in the plasma, similar to BAL, which shows a progressive trend [5], the BM-MSCs transplantation in the ALI model in mice caused the tissue inhibitor expression of metalloproteinase- 1 to decline and the increment expression of metalloproteinase-8 [62] and the levels of myeloperoxidase activity and malondialdehyde reduction and the anti-oxidant enzyme activities to increase [67]. In the another study, a significant decrement in the influx of inflammatory cells (the total white blood cells, neutrophils, lymphocytes, and monocytes) and cytokines/chemokines (MIP-2 and TNF- $\alpha$ ) has been confirmed following the intrapulmonary transplantation of the MSCs after endotoxin administration in mice [71]. These results represent the function of the MSCs to improve the immune system and suggest that despite the transplantation of the cells in the lung, this treatment method has significant systemic effects. Investigating the transplantation of human MSCs in reducing induced-ALI by use of intravenous oleic acid in a pig model displayed that IL-8 elevation acts as a chemokine for neutrophil and is closely related to the intensity and duration of ALI. Therefore, there was a significant relationship between the neutrophil and the IL-8 concentration but a significant decrease in transcription of NF-kB inflammatory factor [37].

\section{The effects of MSC therapy on blood gases situation}

The results of the analysis of blood gases have an important role in the diagnosis and management of pulmonary capacity, the state of oxygenation and the balance of acid and base. The low level of partial pressure of oxygen (PO2) and subsequent high level of and partial pressure of carbon dioxide (PCO2) in the blood can occur due to the decline in gases exchange resulting from inflammation and obstruction of the airways which causes the hypoventilation and dyspnea. If the low level of PO2 (hypoxia) is prolonged, it can cause contraction 
of the blood vessels in the lungs and the pulmonary hypertension [84]. The researchers found that the cell therapy with the MSCs has been able to improve the blood PO2 level through the mediators and inflammation reduction. The stem/stromal cells transplantation induces a similar effect with the bronchodilator drugs and has led to a significant increase in arterial blood oxygenation and a the decrease in carbon dioxide level. They found that in the ARDS experimental model in rabbit that had decreased the $\mathrm{O} 2$ saturation (SatO2) level, the MSCs transplantation has caused a significant increase in the amount of $\mathrm{SatO} 2$ and the arterial blood pressure after $12 \mathrm{~h}$ [5] and also, in ventilation-induced lung injury in rat caused a significant increase in the oxygenation of arterial blood [63]. The PCO2 is evaluated for the pulmonary ventilation condition and as an the effective respiratory component in the regulation of blood acidity. In the pulmonary diseases, hypoventilation leads to imprisonment and accumulation of the $\mathrm{CO} 2$ in the blood (increase PCO2) and a decrease in the $\mathrm{pH}$ (respiratory acidosis). The transplantation of MSCs in the ARDS of rabbit caused deep and fast respiration (hyperventilation) which increased the $\mathrm{CO}_{2}$ elimination (decreased $\mathrm{PCO}_{2}$ ) and resulted in an increase in the blood $\mathrm{pH}$ [5]. Li et al., also stated that the use of MSCs in inflammation caused by H9N2 avian influenza in mice decreases the lung physiological dysfunction indices and increases the lung capability [52].

\section{The effects of MSC therapy on edema and inflammations of the lung}

Tomography is used to represent the heterogeneous patterns in the pulmonary diseases. The computed tomography scan (CT-scan) can provide valuable diagnostic information in the patients with pulmonary diseases, various stages of disease, improvement, or complications for the clinicians. In the CT-scan studies, increasing the Honsfield unit confirms the replacement of alveolar air with the mucus and inflammatory cells and the mean volume of lung increases as a result of edema and inflammation [85]. Accordingly, the examination of the lung CT-scan at different times post-MSCs therapy in the ARDS model in the rabbit demonstrated a significant decrement in Honsfield unit 1 week after transplantation, that confirmed the effect of the stem/stromal cells in reduction of the pulmonary inflammation and edema [5].

The evaluation of histopathology after the cellular treatment of the pulmonary inflammation in mice revealed a significant decrease in inflammatory exudate and interstitial edema, decline in the thickness of the wall between the alveolar [30,59] and a significant reduction in the neutrophils of the lung compared with the control group. However, the histopathological study did not reveal significant statistical differences in the pig model [37]. Also, the pathological findings of Li et al. showed that the MSCs-based therapy could help to lessen the lung histopathologic changes, including reduced lung inflammation and the pulmonary vascular permeability, and help in the treatment of H9N2 avian influenza, but the correlation of their data was not statistically significant [52] and Shalaby et al. showed the BM-MSCs protect anatomical structure of the lung in E.coli-induced ALI in mice [67]. Also, the intravenous transplantation of adipose tissue-derived MSCs in the model of endotoxin-induced ALI in mice lead to the least infiltration of inflammatory cells, no apoptosis, and maintained lung architecture [64]. In another study in the ARDS model in rabbit, the absence of calcification or granulation formation and the subacute and chronic granulomatous reactions, the reduction of inflammation and hemorrhage, and the frequent hotspots of ATII cells production after the MSCs transplantation compared to control group was reported. They stated that the lung probably responds well to transplantation of the MSCs due to its anatomical structure and in this regard better blood supply, less connective tissue, less lobulation, the alveolar relationship to each other, having the side ventilation and the ease of access to blood factors (humoral and cellular factors) have a role [5].

\section{Conclusion}

This review revealed that the MSCs play an important role in the repair of the acute lung injuries. So that, these cells prevent the progression of inflammation and edema and improve the clinical signs and the local and systemic inflammatory factors. The released agents by the MSCs play a the crucial role in the repair of injury through the properties of anti-inflammatory, antiapoptosis, angiogenesis and the immune system modification, and also, the lung damage can be improved by the ability of the MSCs to differentiate to the cells of lung epithelium and endothelial. However, although many advances have been made in the treatment of acute pulmonary diseases using the MSCs, and it is considered a safe and effective treatment method, more preclinical trials are needed to find the best cell source, the cell culture and suitable passage, the storage conditions, the cell count, the method of transplantation and cell transfer time. So the present review, along with the complementary reports, can use the MSCs therapy for the treatment of acute lung diseases in the future.

\footnotetext{
Abbreviations

MSCs: Mesenchymal Stem/Stromal Cells; ARDS: Acute Respiratory Distress Syndrome; PMNs: PolyMorphonuclear Leukocytes; ATII: Alveolar Type II; ATI: Alveolar Type I; BADJ: Bronchoalveolar Duct Junction; COPD: Chronic Obstructive Pulmonary Disease; IPF: Idiopathic Pulmonary Fibrosis; BPD: Bronchopulmonary Dysplasia; CF: Cystic Fibrosis; LPS: Lipopolysacaride; (TNF-a): Tumor Necrosis Factor-a; IDO: Indolearnine 2,3-dioxygenase; IL2: Interlukine-2; IL-10: Interlukine-10; CCL18: Chemokine (C-C motif) ligand 18; PGE2: Prostaglandin E2; KGF: Keratinocyte Growth Factor; ALI: Acute Lung
} 
Injury; E.coli: Escherichia coli; BM-MSCs: Bone Marrow Mesenchymal Stem/ Stromal Cells; BAL: Bronchoalveolar Lavage; GFP: Green Fluorescent Protein NETs: Neutrophil Extracellular Traps; IFN-ү: Interfron- $\gamma ;$ IgM: Immunoglobulin M; MIP-2: Macrophage Inhibitory Protein-2; UC-MSCs: Umbilical Cord Mesenchymal Stem/Stromal Cells; NF-kB: Nuclear Factor kappa B; GMCSF: Granulocyte Macrophage Colony Stimulating Factor; G-CSF: Granulocyte Colony Stimulating Factor; PO2: partial pressure of Oxygen; PCO2: partial pressure of Carbon dioxide; SatO2: O2 Saturation; CT-scan: Computed Tomography scan

\section{Acknowledgements}

Not applicable.

\section{Authors' contributions}

Sirous Sadeghian Chaleshtori; The study design, performed literature review and prepared the initial, revision and finalization manuscript. Mohammad Reza Mokhber Dezfouli; The conception and design of the study, commented on the data analysis and the revision and finalization of the manuscript. Massoumeh Jabbari Fakhr; Performed literature review and analysis, drafting and critical revision and editing. All authors read and approved the final manuscript.

\section{Funding}

No funding was received.

\section{Availability of data and materials}

Authors want to share their data.

\section{Ethics approval and consent to participate}

Not applicable.

\section{Consent for publication}

Not applicable.

\section{Competing interests}

The authors declare that they have no competing interests.

\section{Author details}

'Department of Internal Medicine, Faculty of Veterinary Medicine, University of Tehran, Tehran, Iran. ${ }^{2}$ Institute of Biomedical Research, Faculty of Veterinary Medicine, University of Tehran, Tehran, Iran. ${ }^{3}$ Department of Tissue Engineering, Faculty of Medicine, Qom University of Medical Sciences, Qom, Iran.

Received: 16 December 2019 Accepted: 23 April 2020

Published online: 11 May 2020

\section{References}

1. Dushianthan A, Grocott MP, Postle AD, Cusack R. Acute respiratory distress syndrome and acute lung injury. Postgrad Med J. 2011;87:612-22.

2. Mokhber Dezfouli MR, Chaleshtori SS, Dehghan MM, Tavanaeimanesh H, Baharvand $\mathrm{H}$, Tahamtani Y. The therapeutic potential of differentiated lung cells from embryonic stem cells in lung diseases. Curr Stem Cell Res Ther. 2017;12:80-4.

3. Sadeghian Chaleshtori S, Dezfouli MR, Dehghan MM, Tavanaeimanesh $\mathrm{H}$. Generation of lung and airway epithelial cells from embryonic stem cells in vitro. Crit Rev Eukaryot Gene Expr. 2016;26:1-9.

4. Lee JW, Fang X, Gupta N, Serikov V, Matthay MA. Allogeneic human mesenchymal stem cells for treatment of E. coli endotoxin-induced acute lung injury in the ex vivo perfused human lung. Proc Natl Acad Sci U S A. 2009;106:16357-62.

5. Mokhber Dezfouli MR, Jabbari Fakhr M, Sadeghian Chaleshtori S, Dehghan MM, Vajhi A, Mokhtari R. Intrapulmonary autologous transplant of bone marrow-derived mesenchymal stromal cells improves lipopolysaccharideinduced acute respiratory distress syndrome in rabbit. Crit Care. 2018;22:353.

6. Bernard GR, Artigas A. The definition of ARDS revisited: 20 years later. Intensive Care Med. 2016;42:640-2.

7. Matthay MA, Zemans RL. The acute respiratory distress syndrome: pathogenesis and treatment. Annu Rev Pathol. 2011;6:147-63.

8. Kinoshita M, Ono S, Mochizuki H. Neutrophils mediate acute lung injury in rabbits: role of neutrophil elastase. Eur Surg Res. 2000;32:337-46.
9. Gonzales JN, Lucas R, Verin AD. The acute respiratory distress syndrome: mechanisms and perspective therapeutic approaches. Austin J Vasc Med. 2015;2.

10. Abraham E. Neutrophils and acute lung injury. Crit Care Med. 2003;31:S195-9.

11. Kamaruzaman NA, Kardia E, Kamaldin N, Latahir AZ, Yahaya BH. The rabbit as a model for studying lung disease and stem cell therapy. Biomed Res Int. 2013;2013:691830.

12. Saguil A, Fargo M. Acute respiratory distress syndrome: diagnosis and management. Am Fam Physician. 2012;85:352-8.

13. Lee WL, Downey GP. Leukocyte elastase: physiological functions and role in acute lung injury. Am J Respir Crit Care Med. 2001;164:896-904.

14. Bein T, Grasso S, Moerer O, Quintel M, Guerin C, Deja M, Brondani A, Mehta S. The standard of care of patients with ARDS: ventilatory settings and rescue therapies for refractory hypoxemia. Intensive Care Med. 2016;42:699-711.

15. Cruz FF, Weiss DJ, Rocco PR. Prospects and progress in cell therapy for acute respiratory distress syndrome. Expert Opin Biol Ther. 2016;16:1353-60.

16. Hayes M, Curley G, Ansari B, Laffey JG. Clinical review: stem cell therapies for acute lung injury/acute respiratory distress syndrome - hope or hype? Crit Care. 2012;16:205.

17. Sueblinvong $V$, Weiss DJ. Stem cells and cell therapy approaches in lung biology and diseases. Transl Res. 2010;156:188-205.

18. Wang D, Morales JE, Calame DG, Alcorn JL, Wetsel RA. Transplantation of human embryonic stem cell-derived alveolar epithelial type II cells abrogates acute lung injury in mice. Mol Ther. 2010;18:625-34.

19. Sdrimas K, Kourembanas S. MSC microvesicles for the treatment of lung disease: a new paradigm for cell-free therapy. Antioxid Redox Signal. 2014; 21:1905-15.

20. Goolaerts A, Pellan-Randrianarison N, Larghero J, Vanneaux V, Uzunhan Y, Gille T, Dard N, Planes C, Matthay MA, Clerici C. Conditioned media from mesenchymal stromal cells restore sodium transport and preserve epithelial permeability in an in vitro model of acute alveolar injury. Am J Physiol Lung Cell Mol Physiol. 2014;306:L975-85.

21. Biehl JK, Russell B. Introduction to stem cell therapy. J Cardiovasc Nurs. 2009:24:98-103 quiz 104-105.

22. Alvarez A, Unda F, Canavate ML, Hilario E. Stem cell and regenerative medicine. Curr Stem Cell Res Ther. 2009;4:287-97.

23. Snyder JC, Teisanu RM, Stripp BR. Endogenous lung stem cells and contribution to disease. J Pathol. 2009;217:254-64.

24. Wang J, Edeen K, Manzer R, Chang Y, Wang S, Chen X, Funk CJ, Cosgrove GP, Fang X, Mason RJ. Differentiated human alveolar epithelial cells and reversibility of their phenotype in vitro. Am J Respir Cell Mol Biol. 2007;36: $661-8$.

25. Kotton DN, Ma BY, Cardoso WV, Sanderson EA, Summer RS, Williams MC, Fine A. Bone marrow-derived cells as progenitors of lung alveolar epithelium. Development. 2001;128:5181-8.

26. Eggenhofer E, Luk F, Dahlke MH, Hoogduijn MJ. The life and fate of mesenchymal stem cells. Front Immunol. 2014;5:148.

27. Zhu H, Xiong Y, Xia Y, Zhang R, Tian D, Wang T, Dai J, Wang L, Yao H, Jiang $\mathrm{H}$, et al. Therapeutic effects of human umbilical cord-derived Mesenchymal stem cells in acute lung injury mice. Sci Rep. 2017.

28. Gupta N, Su X, Popov B, Lee JW, Serikov V, Matthay MA. Intrapulmonary delivery of bone marrow-derived mesenchymal stem cells improvessurvival and attenuates endotoxin-induced acute lung injury in mice. J Immunol. 2007;179(3):1855-63.

29. Phinney DG, Prockop DJ. Concise review: mesenchymal stem/multipotent stromal cells: the state of transdifferentiation and modes of tissue repair-current views. Stem Cells. 2007;25:2896-902.

30. Mei SHJ, McCarter SD, Deng Y, Parker CH, Liles WC, Stewart DJ. Prevention of LPS-induced acute lung injury in mice by Mesenchymal stem cells overexpressing Angiopoietin 1. PLoS Med. 2007;4:e269.

31. Abbasi J, Mokhber Dezfooli MR, Sadeghian Chaleshtori S, Dehghan MM, Vajhi A, Baharvand H, Ghanei M, Jabari Fakhr M. Improvement of clinical signs in experimental model of acute respiratory distress syndrome (ARDS) in sheep following autograft of bone marrow-derived Mesenchymal stem cells (BM-MSCs). J Veterinary Research. 2018;73:17-26.

32. Ponte AL, Marais E, Gallay N, Langonne A, Delorme B, Herault O, Charbord $\mathrm{P}$, Domenech $\mathrm{J}$. The in vitro migration capacity of human bone marrow mesenchymal stem cells: comparison of chemokine and growth factor chemotactic activities. Stem Cells. 2007;25:1737-45.

33. Wagner $W$, Ho AD, Zenke M. Different facets of aging in human mesenchymal stem cells. Tissue Eng Part B Rev. 2010;16:445-53. 
34. Fischer UM, Harting MT, Jimenez F, Monzon-Posadas WO, Xue H, Savitz $\mathrm{SI}$, Laine GA, Cox CS Jr. Pulmonary passage is a major obstacle for intravenous stem cell delivery: the pulmonary first-pass effect. Stem Cells Dev. 2009;18:683-92.

35. Xiang B, Chen L, Wang X, Zhao Y, Wang Y, Xiang C. Transplantation of menstrual blood-derived Mesenchymal stem cells promotes the repair of LPS-induced acute lung injury. Int J Mol Sci. 2017;18.

36. Asmussen S, Ito H, Traber DL, Lee JW, Cox RA, Hawkins HK, McAuley DF, McKenna DH, Traber LD, Zhuo H, et al. Human mesenchymal stem cells reduce the severity of acute lung injury in a sheep model of bacterial pneumonia. Thorax. 2014.

37. Moodley Y, Sturm M, Shaw K, Shimbori C, Tan DB, Kolb M, Graham R. Human mesenchymal stem cells attenuate early damage in a ventilated pig model of acute lung injury. Stem Cell Res. 2016;17:25-31.

38. Chien MH, Bien MY, Ku C-C, Ku CC, Chang Y-C, Pao H-Y, Yang Y-L, Hsiao M, Chen C-L, Ho JH. Systemic human orbital fat-derivedstem/ stromal cell transplantation ameliorates acute inflammation in lipopolysaccharide-induced acute lung injury. Crit Care Med. 2012;40(4): 1245-53.

39. Xu J, Qu J, Cao L, Sai Y, Chen C, He L, Yu L. Mesenchymal stem cell-based angiopoietin-1 gene therapy for acute lung injury induced by lipopolysaccharide in mice. J Pathol. 2008;214:472-81.

40. Eggenhofer E, Benseler V, Kroemer A, Popp FC, Geissler EK, Schlitt HJ, Baan CC, Dahlke MH, Hoogduijn MJ. Mesenchymal stem cells are short-lived and do not migrate beyond the lungs after intravenous infusion. Front Immunol. 2012;3:297.

41. Ge W, Jiang J, Arp J, Liu W, Garcia B, Wang H. Regulatory T-cell generation and kidney allograft tolerance induced by mesenchymal stem cells associated with indoleamine 2,3-dioxygenase expression. Transplantation. 2010;90:1312-20.

42. Engela AU, Hoogduijn MJ, Boer K, Litjens NH, Betjes MG, Weimar W, Baan CC. Human adipose-tissue derived mesenchymal stem cells induce functional de-novo regulatory T cells with methylated FOXP3 gene DNA. Clin Exp Immunol. 2013;173:343-54.

43. Nemeth K, Leelahavanichkul A, Yuen PS, Mayer B, Parmelee A, Doi K, Robey $\mathrm{PG}$, Leelahavanichkul $\mathrm{K}$, Koller BH, Brown JM, et al. Bone marrow stromal cells attenuate sepsis via prostaglandin E (2)-dependent reprogramming of host macrophages to increase their interleukin-10 production. Nat Med. 2009;15:42-9.

44. Fang $X$, Neyrinck AP, Matthay MA, Lee JW. Allogeneic human mesenchymal stem cells restore epithelial protein permeability in cultured human alveolar type II cells by secretion of angiopoietin-1. J Biol Chem. 2010;285:26211-22.

45. Ionescu L, Byrne RN, van Haaften T, Vadivel A, Alphonse RS, Rey-Parra GJ, Weissmann G, Hall A, Eaton F, Thebaud B. Stem cell conditioned medium improves acute lung injury in mice: in vivo evidence for stem cell paracrine action. Am J Physiol Lung Cell Mol Physiol. 2012;303: L967-77.

46. Wakayama $\mathrm{H}$, Hashimoto $\mathrm{N}$, Matsushita $\mathrm{Y}$, Matsubara K, Yamamoto N, Hasegawa Y, Ueda M, Yamamoto A. Factors secreted from dental pulp stem cells show multifaceted benefits for treating acute lung injury in mice. Cytotherapy. 2015;17:1119-29.

47. Xu J, Qu J, Cao L, Sai Y, Chen C, He L Yu L: Mesenchymal stem cell-based angiopoietin-1 gene therapy for acute lung injury induced bylipopolysaccharide in mice. J Pathol 2008; 214(4):472-81.

48. Zhou J, Jiang L, Long X, Fu C, Wang X, Wu X, Liu Z, Zhu F, Shi J, Li S. Bonemarrow-derived mesenchymal stem cells inhibit gastric aspiration lung injury and inflammation in rats. J Cell Mol Med. 2016;20:1706-17.

49. Liang ZX, Sun JP, Wang P, Tian Q, Yang Z, Chen LA. Bone marrow-derived mesenchymal stem cells protect rats from endotoxin-induced acutelung injury. Chin Med J. 2011;124(17):2715-22.

50. Li J, Li D, Liu X, Tang S, Wei F. Human umbilical cord mesenchymal stem cells reduce systemic inflammation and attenuate LPS-induced acutelung injury in rats. J Inflamm (Lond) 2012;13;9(1):33.

51. Xu YL, Liu Yl, Wang Q, Li G, Lu X-D, Kong B: Intravenous transplantation of mesenchymal stem cells attenuates oleic acid induced acute lunginjury in rats. Chin Med J (Engl) Chin Med J (Engl) 2012; 125(11):2012-8

52. Li Y, Xu J, Shi W, Chen C, Shao Y, Zhu L, Lu W, Han X. Mesenchymal stromal cell treatment prevents H9N2 avian influenza virus-induced acute lung injury in mice. Stem Cell Res Ther. 2016;7:159.
53. Xu J, Woods CR, Mora Al, Joodi R, Brigham KL, lyer S, Rojas M. Prevention of endotoxin-induced systemic response by bone marrow-derived mesenchymal stem cells in mice. Am J Physiol Lung Cell Mol Physiol 2007; 293(1):L131-41.

54. Krasnodembskaya A, Song Y, Fang X, Gupta N, Serikov V, Lee J-W, Matthay MA: Antibacterial Effect of Human Mesenchymal Stem Cells Is Mediated in Part from Secretion of the Antimicrobial Peptide LL-37. Stem Cells (Dayton, Ohio) 2010, 28:2229-2238.

55. Liang ZX, Sun JP, Wang P, Tian Q, Yang Z, Chen LA. Bone marrow-derived mesenchymal stem cells protect rats from endotoxin-induced acute lung injury. Chin Med J. 2011;124:2715-22.

56. Sun J, Han ZB, Liao W, Yang SG, Yang Z, Yu J, Meng L, Wu R, Han ZC. Intrapulmonary delivery of human umbilical cord mesenchymal stem cells attenuates acute lung injury by expanding CD4+CD25+ Forkhead Boxp3 (FOXP3)+ regulatory $T$ cells and balancing anti- and pro-inflammatory factors. Cell Physiol Biochem 2011; 27(5):587-96.

57. Kim ES, Chang YS, Choi SJ, Kim JK, Yoo Hs, Ahn SY, Sung Dk, Kim SY, Park YR, Park WS: Intratracheal transplantation of human umbilical cord bloodderived mesenchymal stem cells attenuates Escherichia coli-induced acute lung injury in mice. Respir Res 2011; 15;12:108.

58. Danchuk S, Ylostalo Jh, Hossain F, Sorge R, Ramsey A, Bonvillain Rw, Lasky JA, Bunnell BA, Welsh Da, Prockop DJ, Sullivan DE: Human multipotent stromal cells attenuate lipopolysaccharide-induced acute lung injury in mice via secretion of tumor necrosis factor-alpha-induced protein 6. Stem Cell Res Ther 2011; 13;2(3):27.

59. Gupta N, Krasnodembskaya A, Kapetanaki M, Mouded M, Tan X, Serikov V, Matthay MA: Mesenchymal stem cells enhance survival and bacterial clearance in murine Escherichia coli pneumonia. Thorax 2012; 67(6):533-9.

60. Qin ZH, Qu JM, Xu J-f, Xu JF, Zhang J, Summah H, Sai-Yin H-xG, Sai-Yin HX, Chen CM, Yu L: Intrapleural delivery of mesenchymal stem cells: a novel potential treatment for pleural diseases. Acta Pharmacol Sin 2011; 32(5):581-90.

61. Tai WL, Dong ZX, Zhang D-D, Wang DH. Therapeutic effect of intravenous bone marrow-derived mesenchymal stem cell transplantation on earlystage LPS-induced acute lung injury in mice. Nan Fang Yi Ke Da Xue Xue Bao. 2012;32(3):283-90.

62. Maron-Gutierrez T, Silva JD, Asensi KD, Bakker-Abreu I, Shan Y, Diaz BI, Goldenberg RCS, Mei SHJ, Stewart DJ, Morales Mm, Rocco PRM, et al. Effects of mesenchymal stem cell therapy on the time course of pulmonary remodeling depend on the etiology of lung injury in mice. Crit Care Med. 2013;41(11):e319-33.

63. Curley GF, Ansari B, Hayes M, Devaney J, Masterson C, Ryan A, Barry F, O'Brien T, Toole DO, Laffey JG. Effects of intratracheal mesenchymal stromal cell therapy during recovery and resolution after ventilator-induced lung injury. Anesthesiology. 2013;118(4):924-32.

64. Martinez-Gonzalez I, Roca O, Masclans JR, Moreno R, Salcedo MT, Baekelandt V, Cruz MJ, Rello J, Aran JM: Human mesenchymal stem cells overexpressing the IL-33 antagonist soluble IL-1 receptor-like-1 attenuate endotoxininduced acute lung injury. Am J Respir Cell Mol Biol 2013;49(4):552-62.

65. Martinez-Gonzalez I, Roca O, Masclans JR, Moreno R, Salcedo MT, Baekelandt V, Cruz MJ, Rello J, Aran JM. Human mesenchymal stem cells overexpressing the IL-33 antagonist soluble IL-1 receptor-like-1 attenuate endotoxin-induced acute lung injury. Am J Respir Cell Mol Biol. 2013:49:552-62.

66. Chen J, Li C, Gao X, Liang Z, Yu L, Li Y, Xiao X, Chen L. Keratinocyte growth factor gene delivery via mesenchymal stem cells protects against lipopolysaccharide-induced acute lung injury in mice. PLoS One. 2013;18;8(12):e83303.

67. Shalaby SM, El-Shal AS, Abd-Allah SH, Selim AO, Selim SA, Gouda ZA, Abd El Motteleb DM, Zanfaly HE, El-Assar HM, Abdelazim S. Mesenchymal stromal cell injection protects against oxidative stress in Escherichia coli-induced acute lung injury in mice. Cytotherapy. 2014;16:764-75.

68. Zhao YF, Xiong W, Wu XL. Mesenchymal stem cell-based developmental endothelial locus-1 gene therapy for acute lung injury induced by lipopolysaccharide in mice. Mol Med Rep. 2014;9:1583-9..

69. He H, Liu L, Chen Q, Liu A, Cai S, Yang Y, Lu X, Qiu H: Mesenchymal stem cells overexpressing angiotensin-converting enzyme 2 rescuelipopolysaccharide-induced lung injury. Cell Transplant 2015; 24(9): 1699-715.

70. Zhao YF, Luo Ym, Xiong W, Ding W, Li YR, Zhao W, Zeng HZ, Gao HC, Wu $X \mathrm{~L}$ : Mesenchymal stem cell-based FGF2 gene therapy for acutelung injury 
induced by lipopolysaccharide in mice. Eur Rev Med Pharmacol Sci 2015; 19(5):857-65.

71. Hao Q, Zhu Y-G, Monsel A, Gennai S, Lee T, Xu F, Lee J-W. Study of bone marrow and embryonic stem cell-derived human Mesenchymal stem cells for treatment of Escherichia coli endotoxin-induced acute lung injury in mice. Stem Cells Transl Med. 2015;4:832-40.

72. Devaney J, Horie S, Masterson C, Elliman S, Barry F, O'Brien T, Curley GF, O'Toole D, Laffey JG: Human mesenchymal stromal cells decrease theseverity of acute lung injury induced by E. coli in the rat. Thorax 2015; 70(7):625-35.

73. Xiang $B$, Chen $L$, Wang $X$, Zhao Y, Wang Y, Xiang C: Transplantation of Menstrual Blood-Derived Mesenchymal Stem Cells Promotes the Repair of LPS-Induced Acute Lung Injury. LID - E689 LID - https://doi.org/10.3390/ ijms18040689. Int J Mol Sci 2017.

74. Pedrazza L, Cunha AA, Luft C, Nunes NK, Schimitz F, Gassen RB, Breda RV, Donadio MV, de Souza Wyse AT, Pitrez PMC, et al. Mesenchymal stem cells improves survival in LPS-induced acute lung injury acting through inhibition of NETs formation. J Cell Physiol. 2017;232:3552-64.

75. Johnson CL, Soeder Y, Dahlke MH. Concise review: Mesenchymal stromal cell-based approaches for the treatment of acute respiratory distress and Sepsis syndromes. Stem Cells Transl Med. 2017;6:1141-51.

76. Rojas M, XU J, Woods CR, Mora AL, Spears W, Roman J, Brigham KL. Bone marrow-derived mesenchymal stem cells in repair of the injured lung. Am J Respir Cell Mol Biol. 2005;33:145-52.

77. Simonson OE, Mougiakakos D, Heldring N, Bassi G, Johansson HJ, Dalen M, Jitschin R, Rodin S, Corbascio M, El Andaloussi S, et al. In vivo effects of Mesenchymal stromal cells in two patients with severe acute respiratory distress syndrome. Stem Cells Transl Med. 2016;5:845.

78. McIntyre LA, Moher D, Fergusson DA, Sullivan KJ, Mei SH, Lalu M, Marshall J, McLeod M, Griffin G, Grimshaw J, et al. Efficacy of Mesenchymal stromal cell therapy for acute lung injury in preclinical animal models: a systematic review. PLoS One. 2016;11:e0147170.

79. Johnson KA, Yao W, Lane NE, Naquet P, Terkeltaub RA. Vanin-1 pantetheinase drives increased chondrogenic potential of mesenchymal precursors in ank/ank mice. Am J Pathol. 2008;172:440-53.

80. Meyer KC. Bronchoalveolar lavage as a diagnostic tool. Semin Respir Crit Care Med. 2007;28:546-60

81. Monsel A, Zhu YG, Gudapati V, Lim H, Lee JW. Mesenchymal stem cell derived secretome and extracellular vesicles for acute lung injury and other inflammatory lung diseases. Expert Opin Biol Ther. 2016;16:859-71.

82. Hoogduijn MJ, Roemeling-van Rhijn M, Engela AU, Korevaar SS, Mensah FK, Franquesa M, de Bruin RW, Betjes MG, Weimar W, Baan CC. Mesenchymal stem cells induce an inflammatory response after intravenous infusion. Stem Cells Dev. 2013;22:2825-35.

83. Zhang JM, An J. Cytokines, inflammation, and pain. Int Anesthesiol Clin. 2007:45:27-37.

84. Sei K, Fujita M, Okawa S, Hirasawa T, Kushibiki T, Sasa H, Furuya K, Ishihara M. Appropriate timing of blood sampling for blood gas analysis in the ventilated rabbit. J Surg Res. 2016;206:325-36.

85. Caironi P, Carlesso E, Gattinoni L. Radiological imaging in acute lung injury and acute respiratory distress syndrome. Semin Respir Crit Care Med. 2006; 27:404-15.

\section{Publisher's Note}

Springer Nature remains neutral with regard to jurisdictional claims in published maps and institutional affiliations.

\section{Ready to submit your research? Choose BMC and benefit from}

- fast, convenient online submission

- thorough peer review by experienced researchers in your field

- rapid publication on acceptance

- support for research data, including large and complex data types

- gold Open Access which fosters wider collaboration and increased citations

- maximum visibility for your research: over $100 \mathrm{M}$ website views per year

At BMC, research is always in progress.

Learn more biomedcentral.com/submissions 